\title{
The Influence and Suggestions of Mother Tongue on English Translation
}

\author{
Lan Ma \\ Canvard College, Beijing Technology and Business University, 100018
}

\begin{abstract}
Due to the thinking modes differences between English and Chinese, the mother tongue level will interfere with the students at all levels of language. Based on the teaching practice, this paper analyzes the influence of the mother tongue level on the students' translation from three aspects: vocabulary, grammar and sentence structure, and puts forward the strategies to solve them.
\end{abstract}

Keywords: influence, suggestions, mother tongue, English translation

\section{Introduction}

CET-4 has increased the number of Chinese-to-English translations since June 2005. It mainly examines the students 'language output ability, and aims to test the students' vocabulary, phrases, sentences, grammar and idioms in the fourLaw and other knowledge points to master the situation. However, students from the respondents to see the overall score are not high. From the students' examination answers and peacetime teaching exercises, it is found that most of the students have a lot of Chinglish phenomenon in the translation practice, especially the Chinese-English exercises. This is a typical pragmatic mistake caused by the negative transfer of mother tongue. The reason, most of the errors are in accordance with the expression of Chinese habits applied to the English on the result. However, in practice, this situation is still very common in English, for this situation we still need to continue to understand the essence of migration, to explore the negative transfer of our study of the impact of negative transfer on the learning of English learning is very important. 


\section{The Role of Linguistic Competence on English Translation}

Language ability plays an important role in English translation. Chomsky's Transformational Generative Grammar There are two important messages in the definition of language competence:

The formation of cognitive ability of language skills, language ability refers to a person's mind has been internalized in a language grammar; language ability is the people's minds inherent grammar knowledge.

Language skills include intuition or sense of language, the mother tongue user has a intuitive way to play a role and effective knowledge of the basic system of language; language ability to the ideal language user's sense of the standard.

In the process of English-Chinese translation, linguistic competence is embodied in the accurate understanding of the source language of translation. This understanding is not necessarily embodied in a strict form of text, but a cognitive mechanism existing in the translator's brain, as many people can read Foreign language articles, but not necessarily accurate with the source language or target language retell out the same. At the same time, linguistic competence is also important in the process of translation into the target language. When the translator understands the source language and wants to express it in the target language, it needs to have the language sense of the target language user. The target language of the ability of English-Chinese translation of the natural means of Chinese ability, for our translators, is the mother tongue ability.

\section{The Relationship between Native Language Competence and English Translation}

According to our experience in English-Chinese translation practice, the process of English-Chinese translation can be divided into three stages: the stage of comprehension and analysis of source language, English, and the comparative analysis of English and Chinese, including cultural contrast; with the target language, the expression of the Chinese stage. And mother tongue ability plays an important role in these three stages.

The first stage is the understanding and analysis of English, which requires the translator to have a good foundation in English, and English learning also needs a high level of Chinese. Whether it is based on the theory of behaviorist psychology based on empirical teaching theory or cognitive psychology as the theoretical basis of the cognitive theory of teaching, they all believe that mother tongue in foreign language learning has a crucial role.

Cognitive grammar translation method advocates learning new knowledge from the existing knowledge of students, that mother tongue are the second language learners have the knowledge, should be widely used in teaching. The theoretical basis of the rejection of the native-speaking experientialists is structuralism linguistics and behaviorist psychology, and language is habit. Learning English means cultivating a new language habit independent of Chinese. 
Comparative analysis theory is based on the theory that the mother tongue and the target language have the same or similar parts, learners will easily learn, different or different parts of the larger, the learner will be difficult to grasp. Although this theory was later criticized, but the mother tongue on the impact of foreign language learning cannot be ignored. With the development of cognitive science and psychology, people have come to realize that language is essentially creative. Every sentence that people say is almost always new. Learners' original knowledge is bound to be the reference of new knowledge. In English learning, the role of putting aside the mother tongue, both in theory and practice are not possible.

Without a high level of native language, it is clear that there is no sufficient comparison. As Chinese students begin to learn English, they already have a set of Chinese rules. Therefore, English learning is often the mother tongue as a starting point, mother tongue knowledge is to understand and master the premise of knowledge and background knowledge of English. Whether it is learning English or translating English, the translator must first learn to use a foreign language to think, that is gradually out of the negative transfer of mother tongue thinking. However, the English-Chinese translation is not exactly the same as English learning. It needs to be expressed in Chinese. Therefore, the process of getting rid of mother-tongue thinking, including the limitation of mother-tongue expression, will be negatively negated, that is, not only in English but also in English. Know how to do it.

\section{The Influence of Mother Tongue on English Translation}

\subsection{The lexical level}

English beginners generally believe that English vocabulary is one-on-one, but some of the traditional cultural or political characteristics of the words, it is difficult to find exactly the corresponding vocabulary. Even if found with the corresponding vocabulary, its meaning may be very different. Leech divided the meaning into seven categories, and conceptual meaning was only one of the most important categories. In addition, there are connotative meaning, social significance, with meaning. Some words mean similar surface, but because of different cultural backgrounds, social and historical factors, or different combinations, the actual meaning and emotional colour will be very different.

\subsection{Grammar level}

Modern English is an analytical language, but under the influence of Old English, many forms of inflectional form are retained in the grammar. The means of realization of grammar mainly depend on the change of the form, such as singular and plural of nouns, , Tense, etc .; and Chinese is one of the strongest analytical language, grammar mainly by means of words and word order to express. 
Subject-predicate consistency in English requires the subject and predicates to be consistent in grammatical form and meaning. Nouns are divided into countable nouns and uncountable nouns, and countable nouns are singular and plural. These grammatical rules are not in Chinese, this time negative transfer of mother tongue will occur. There are tenses in both English and Chinese, but in different forms. The tenses in English mainly rely on the change of the word form to express various tenses. Therefore, students not only have to master the verb form, but also grasp the past tense, participle and progressive form of the verb. The tense of the Chinese language is achieved by means of increasing the vocabulary, and you can add that time vocabulary.

\section{3 Sentence structure level}

English sentence organization information is generally based on the tone of the severity of the need to express the most prominent and most important part in front of the sentence expression patterns are generally: subject + predicate + object + adverbial; and Chinese sentence organization is different, generally logical It is a logical sequence, which reflects the temporal structure of real life directly. The sentence expression pattern is generally: subject + adverbial + predicate + object.

\section{Suggestions on Reducing Negative Effects of Mother Tongue on English Translation}

\subsection{Train students' English thinking ability}

Language and thinking are closely linked, complement each other. There are many reasons for the negative transfer of mother tongue, but in the final analysis, it is because the learners use the usual Chinese mode of thinking to use the English language expressly, resulting in violation of English grammar or expression of Chinese customs. Foreign Language Learning Process Should Lay Stress on Cultivating Thinking. In the process of teaching, teachers should try to create a good environment for students to develop independent learning ability, to provide independent thinking space, creating a lively language atmosphere, through multimedia equipment to the real context of the topic, enhance learning interest. At the same time, encourage students to class in English communication, through continuous imitation and use of language, stimulate and train English thinking.

\subsection{Comparing the English and Chinese languages in class}

The direct reason for the negative transfer of mother tongue is due to the differences of the English and Chinese languages at all levels. Students can understand the commonness and individuality of the two languages in terms of vocabulary, grammar, sentence structure, cultural background and so on, and 
understand the similarities and differences between English expressions and sentences and make better use of the usage laws of language. Only by constantly strengthening the students' understanding of this difference can the students understand the reasons for the negative transfer of mother tongue in the translation process and gradually eliminate them, so as to improve the translation ability.

\subsection{Introduction of translation theory in teaching}

In the practice of college English translation, non - English majors' training of translation skills is only limited to the translation practice of each course. The lack of flexibility, universality or disillusionment, or fragmented sentences, one of the reasons is the lack of basic translation theory and techniques of guidance. Only by mastering the basic theories and skills of translation can we fundamentally improve our own translation level. Teachers can focus on the translation skills, so that students do the appropriate exercises, in practice, master and deepen the use of translation techniques and methods.

\section{Conclusion}

On the one hand, the training and training of translation ability need to be focused and realized in English teaching. Teachers need to guide the students to pay attention to the differences of English and Chinese thinking and language structure from both macro and micro levels and improve the efficiency of language use. On the other hand, students need to read extensively under their own classes. They should cultivate their English thinking through exposure to authentic English. At the same time, they should improve their mother tongue level and be able to switch between the two languages more freely.

\section{References}

[1] Dai Weidong, Wang Dong.Language Transfer Research: Problems and Thinking. Foreign Language, 55(12), pp.68-70, 2011

[2] Tang Chengxian. Second language acquisition in the study of the mother tongue transfer. Journal of PLA Foreign Languages Institute, 8 (5), pp.87- 91, 20013

[3] Odlin, T. Language transfer: Cross-languistic influence in language learning. Shanghai: Foreign Language Education. 12(10), pp. 18- 20, 2012

[4] Richards, J.C. (Ed) Longman dictionary of language teaching \& applied linguistics. Singapore: Longman. 9(6), pp.58- 61, 2011

[5] Dai Weidong, Cai Longquan, Cognitive Basis of Inter-language, "Foreign Language and Foreign Language Teaching". 8(4), pp.85-87, 2014 